УДК 37.013 .78

DOI: $10.18101 / 1994-0866-2019-4-78-88$

\title{
МОЛОДЕЖНАЯ КОММУНИКАЦИЯ В УСЛОВИЯХ СОВРЕМЕННОЙ ИНФОРМАЦИОННОЙ СРЕДЫ
}

\author{
(C) Иванова Галина Александровна \\ кандидат педагогических наук, доцент, \\ Санкт-Петербургский институт (филиал) ВГУЮ (РПА Минюста России) \\ Россия, 199178, г. Санкт-Петербург, В. О., 10-я линия, 19 лит. А \\ E-mail: iriza63@mail.ru

\section{(C) Захарова Ирина Борисовна} \\ кандидат философских наук, доцент, \\ Санкт-Петербургский политехнический университет Петра Великого \\ Россия, 195251, г. Санкт-Петербург, ул. Политехническая, 29 \\ E-mail: iriza63@mail.ru
}

\begin{abstract}
Массовая коммуникация, являющаяся одним из типов коммуникации, во многом определяет сущность современного типа социальности и специфику «информационного общества» современности в постиндустриальной эпохе. В условиях нарастающего объема информации, усиления агрессивного воздействия информационной среды необходимо пересмотреть подходы к социализации подрастающего поколения с точки зрения формирования у них новых компетенций, которые позволят молодежи коммуницировать безопасно, этично и взаимовыгодно. Токсичная информационная среда порождает дисфункциональные, токсичные коммуникации, проявляющиеся в пренебрежении этическими нормами взаимодействия, отсутствии у молодых людей гибкости в общении, снижении уровня эмпатии, желании доминировать и усилении вербальной агрессии. В целом разрушается пластичность психики, т. е. способность к переменам, переключения, компенсации и восполнения выносливости психики и формирования социального интеллекта. В этой связи формирование навыков названной нами «эластичной» коммуникации у молодежи становится задачей не только отдельных социальных институтов, таких как семья, образование и средства массовой информации, но и всего общества в целом. В статье авторы приводят примеры коммуникативных технологий, составляющих основу эластичной коммуникации, направленных на понимание участниками коммуникаций понятий личной коммуникативной безопасности и коммуникативной этики, формирование коммуникативного сознания и овладение риторическим коммуникативным поведением, как в реальной жизни, так и в виртуальном пространстве.

Ключевые слова: коммуникативная безопасность личности; токсичная среда; эластичная коммуникация; медиация; рефрейминг; троллинг.
\end{abstract}

\section{Для цитирования}

Иванова Г. А., Захарова И. Б. Молодежная коммуникация в условиях современной информационной среды // Вестник Бурятского государственного университета. Философия. 2019. Вып. 4. С. 78-88.

Цель статьи - рассмотреть коммуникативные технологии, обеспечивающие формирование навыков эластичной коммуникации как средства социализации молодого поколения в условиях усиления токсичности среды. 
Г. А. Иванова, И. Б. Захарова. Молодежная коммуникация в условиях современной информационной среды

Актуальность темы связана с тем, что уровень агрессии в обществе возрастает по мере обесценивания сложившихся нравственных норм и ценностей. Разрушается пластичность психики, т. е. способность к переменам, переключения, компенсации и восполнения выносливости психики и формирования социального интеллекта. Нечто похожее переживает российское общество, находящееся в условиях, когда отмирает старая идеология с ее целями и ценностными ориентирами, а новая еще не оформилась. Несмотря на то, что прошло двадцать восемь лет после распада Советского Союза и мы живем в новых, принципиально иных социально-экономических и политических реалиях, этого времени недостаточно для формирования новой идеологической самоидентификации государства и народа. Идеология связана с этикой самым тесным образом. Мораль определяет, что такое хорошо и что плохо, устанавливает моральные табу и границы дозволенного. Государство, формируя свою идеологию, связывает моральные нормы общей целью, определяет ценностные ориентиры, продвигает и поддерживает ее в обществе.

К сожалению, современное российское общество существует в ситуации вседозволенности и допустимости. Ежедневная лента новостей полна сюжетов о злобе, агрессии и нетерпимости. Каждый социальный слой и группа имеет свои объекты для ненависти. Изменение сакрального статуса педагогов, врачей и представителей других социально значимых профессий привело к тому, что образовательное или медицинское учреждение стало общественным местом, где можно публично выяснять отношения с кем угодно и как угодно. Агрессию и ненависть генерируют многочисленные телевизионные ток-шоу, участники которых, не стесняясь в выражениях, выносят на всеобщее обсуждение события личной и даже интимной жизни. Интернет и социальные сети, где стало возможным все - выплески вербальной агрессии, потоки брани, издевательский информационный троллинг, окончательно открыли общество, сняв все приличия и табу. Нарушение правил, потеря ориентиров заставляют человека нервничать, у него снижается уровень доверия даже к близким людям, от которых, судя по информации в СМИ и социальных сетях, тоже можно ожидать лжи, предательства, обмана и «подставы», происходит привыкание к насилию как необходимому атрибуту общественной жизни. Дезориентированный человек перестает понимать, в каком мире он живет и какие ценности разделяет. Экзистенциальный вакуум в головах людей, особенно молодежи, приводит к тому, что именно подрастающее поколение легко становится объектом манипуляций. Обучение молодежи навыкам эластичной, т. е. безопасной, этичной, эффективной, коммуникации посредством применения в практике общения современных коммуникативных технологий может быть средством социализации подрастающего поколения с целью формирования у него базовых ценностных ориентиров.

В современной культуре, коммуникациях, языках и текстах, сформировавшихся в условиях становления информационного общества, происходит активное овладение разнообразными формами коммуникации в свободных, востребованных культурной средой сочетаниях знаков. Условия диалога в гуманитарной образовательной среде вуза обеспечиваются путем преднамеренного конструирования субъект-субъектных отношений, обусловливающих характер индивидуальноличностных изменений преподавателя и студента. Понятие «паритетность», принятое в теории коммуникации, в образовании интерпретируется как «педагогика 
сотрудничества» в процессе совместной учебной деятельности. Учебно-коммуникативная среда вуза как организованная среда позволяет моделировать коммуникативные ситуации, благодаря анализу которых молодое поколение знакомится с разными примерами социального взаимодействия, новыми понятиями, рисками и угрозами токсичной коммуникации, преимуществами эластичной коммуникации, получает возможность в учебном процессе отработать практические навыки эффективного общения. В частности, успешное овладение риторическим коммуникативным поведением формирует продуктивное коммуникативное сознание, включающее в себя понимание личной коммуникативной безопасности, коммуникативной этики и паритетности.

Благодаря бурному развитию средств массовой коммуникации, особенно интернета и социальных сетей, происходят преобразования в культурном пространстве современного общества, где на первый план выходит не только социально ориентированная деятельность человека, но и деятельность, связанная с производством, осмыслением, передачей и хранением информации. Такие понятия, как информационная безопасность, финансовая безопасность, личная безопасность, прочно вошли в сознание современных людей. Однако информационное общество несет с собой новые социальные изменения, сопряженные с увеличивающимся потоком информации и возможностью ею обмениваться. Интернет и социальные сети привели к резкому повышению уровня коммуникаций в глобальном пространстве, а бесконтрольность этих средств массовой коммуникации открыла возможность широкому распространению токсичного общения, противостоять которому молодое поколение не может.

По мнению специалистов, увеличение доли вербального общения за счет расширения интернет-коммуникаций предполагает знание законов построения риторической речи, которая выступает гарантом безопасности речи, т. к. формирует компетенции в выборе языковых средств из партитуры риторических фигур. Классические риторики доминировали до конца XVIII в. Затем «эпоха готового слова» (Михайлов А. В., 1988) уступила место эпохе авторской стилистики (появление идиостиля), которую мы назовем эпохой «творимого слова» (XIX в.), современная эпоха - это «культура интерпретации готового слова» (Анненкова И. В., 2012).

Особым коммуникативным качеством можно назвать уместность - выбор языковых средств, отвечающих целям и условиям общения: соответствие теме сообщения, его логическому и эмоциональному содержанию, фактор адресата-собеседника и пр. Различают уместность стилевую, контекстуальную, ситуативную и личностно-психологическую. Стилевая уместность - соответствие словесного выражения информации жанру и стилю (функциональной разновидности) литературного языка. Контекстуальная - соответствие речевому окружению (социально-культурному, национально-культурному, политико-идеологическому контексту). Ситуативная - соответствие конкретной ситуации формального или неформального общения (тема, цель, адресат, место, время). Коммуникативно-психологическая — «уместность слога» - в риторике: выбор/соответствие способа выражения (языкового и внеязыкового эмоционально-психологического, интонационного, кинесического) ожиданиям аудитории.

Отметим, что риторическое понимание правильности отличается от общеязыкового тем, что риторический текст существует в системе отношений говоря- 
Г. А. Иванова, И. Б. Захарова. Молодежная коммуникация в условиях современной информационной среды

щий↔слушающий: правильным будет то, что оценено слушающим в качестве такового. Говорящий, помимо эксплицитной (словесно выраженной) языковой информации, вербализует также интерпретирующее, подтекстовое и контекстуальное содержание языковой информации. При этом дискурс включает в себя различные типы информации - психологические, социальные, нормативные, моральноэтические и т. п.

Таким образом, в условиях информатизации общества стало востребованным риторическое коммуникативное поведение как специально организованное коммуникативно-целесообразное (ситуативное), персуазивное (от англ. persuasion «уговаривание, убеждение») поведение. Такое поведение основано на правдоподобных аналитических рассуждениях, нравственно обоснованных, подводящих «ненасильственным» путем (посредством коммуникативных стратегий убеждения и «обольщения») к принятию решения о необходимости/желательности поступка или отказа от совершения определенного посткоммуникативного действия в интересах адресанта» [1].

Педагогическая общественность наработала достаточное количество профессиональных технологий и приемов, позволяющих обучить молодых людей эластичной коммуникации. В «Полном словаре иностранных слов» (2009) на сайте АКАДЕМИК, вошедших в употребление в русском языке, «эластичный» трактуется: 1) как «растяжимый, сохраняющий свой вид и форму, когда его перестают сжимать или растягивать; 2) упругий, гибкий, растяжимый; 3) перен. плавный, мягкий, лишенный резкости. Синонимы - гибкий, легкий, мягкий, нежесткий, плавный, пружинистый, растяжимый, упругий - имеют непосредственное отношение к коммуникации, выбору стратегии и тактики риторической коммуникации.

Эластичная коммуникация понимается нами как продуктивная модель общения людей, способствующая достижению участниками коммуникаций взаимопонимания за счет овладения гуманистическими и этическими коммуникативно-риторическими техниками в целях формирования пластичности коммуникативного поведения в реальной и виртуальной среде и обеспечения коммуникативной безопасности личности.

В данной статье раскроем возможности техники медиации и ситуационного анализа в рамках фреймового подхода к моделированию учебной коммуникации. Медиачия является такой технологией, которая представляет собой набор уникальных навыков по управлению эмоциональными состояниями людей и собственным состоянием. Медиация предполагает владение рядом операций: гашение эмоциональных реакций, быстрое принятие человеком нужного решения, быстрый выбор техник коммуникации, оценка адекватности ситуации. Эти навыки универсальны и могут успешно применяться в коммуникативном поведении для достижения необходимых результатов. Особенно значимо, что медианные навыки становятся компонентом синергии множества навыков из различных областей профессиональных компетенций.

Еще одна технология, расширяющая арсенал безопасного и эластичного коммуникативного поведения, - ситуационный анализ (кейс-технология). Использование ситуационного подхода в обучении позволяет решить целый ряд важнейших образовательных задач: во-первых, уменьшить разрыв между теорией и практикой, во-вторых, сформировать у студентов умения и навыки оценки ситуации, выбора 
и организации ключевой информации, определения перспективных проблем и путей их решения и т. д. Значительным преимуществом метода кейс-стади (case study) является то, что это всегда интерактивное обучение. В частности, практическая задача кейса содержит небольшой или средний объем информации о реальной ситуации, на основе которой студенты должны выполнить некоторое задание по теме. Приведем пример работы с таким кейсом. Задание для групповой работы:

1-й кейс - выявление проблемы на основе анализа текстовых фрагментов: «Важнейший вопрос - обеспечение этической безопасности в контексте проблематики устойчивого развития. Безопасность - это общесистемное свойство, характеризующее все сферы человеческой деятельности. Вопросы этической безопасности приобретают особое звучание в период кризиса» [7].

2-й кейс. Этапы работы с кейсом:

1. Этап: разделение группы студентов на малые группы. Постановка задачи - изучение активно используемого интернет-сленга среди молодежи (на примере блога KtoNaNovenkogo.ru.) Задание: Проанализируйте «троллинг» как форму социальной провокации или издевательства в сетевом общении.

2. Этап: определение основных вопросов работы малой группы:

Понятие и содержание троллинга. Изображение trollface, созданное в 2008 г. художником Whynne часто используется для обозначения троллинга в современной интернет-культуре, что можно увидеть на рисунке 1 :

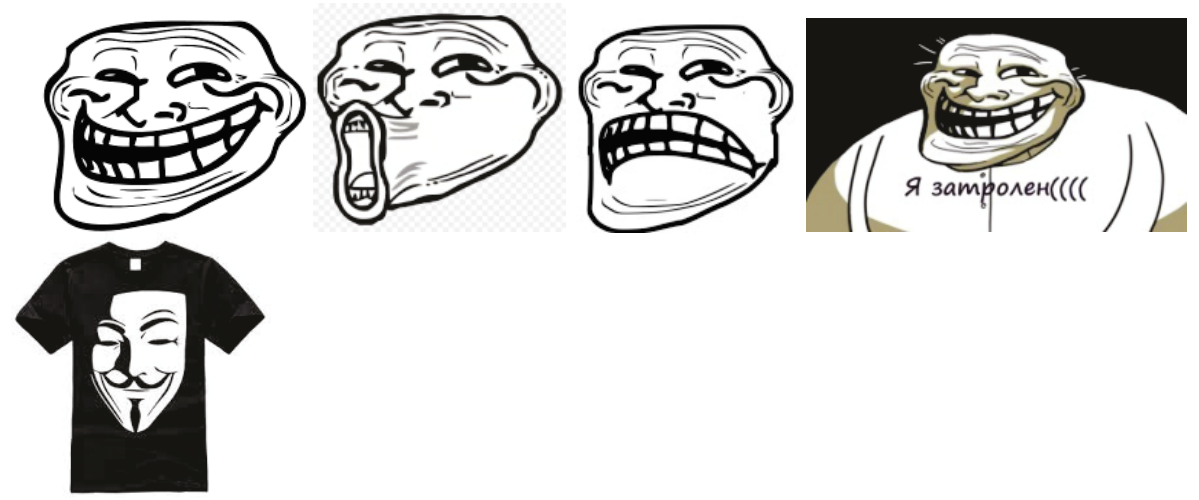

Рис. 1. Обозначения «звериного оскала» троллинга в современной интернет-культуре

Цели троллинга. Он используется как персонифицированными участниками, заинтересованными в большей узнаваемости, публичности и эпатаже, так и анонимными пользователями без возможности их идентификации.

Правила поведения с ситуачии троллинга. Для противодействия троллингу виртуальное сообщество выработало единое правило, которое гласит: не кормите тролля. То есть никогда не вступайте в коммуникацию, если видите, что она тупиковая, оскорбительная и не ведет ни к какому позитивному результату (т. е. общение является контрпродуктивным). Другое дело, как все это понимать, на что именно реагировать и что конкретно делать. Что значит не кормить? «Банить» (так 
Г. А. Иванова, И. Б. Захарова. Молодежная коммуникация в условиях современной информационной среды

чаще всего поступают мужчины)? Или, наоборот, не замечать «звериного оскала» и продолжать с ним общаться как с достойным участником коммуникации?» ${ }^{1}$.

3. Этап: сообщения модераторов групп по результатам работы с кейсами.

4. Этап: общая дискуссия по вопросу: Возможно ли обеспечить этическую коммуникативную безопасность личности в Сети? Обоснуйте ответ.

5. Этап: рефлексия. В ходе рефлексии следует особенно подчеркнуть, что тролли, как правило, используют и выражают психологию газлайтинга - унижающего отношения к собеседнику как «неадеквату», «придурку», «идиоту», отказывая ему в праве на самоидентичность, способность познания истины и уникальность. Газлайтинг можно отнести к разновидности токсичной коммуникации отравляющей человека негативной эмоцией, заражающей страхом, неуверенностью, чувством вины. «Отравитель» выступает с позиции самоуверенного доминирования, чувства превосходства, не оставляя свободы выбора. Слово «toхіс», по версии кураторов Оксфордского словаря, стало словом 2018 г.: «Одним из самых ярких образов в кино и сериалах последних лет стала "фабрика троллей" - предприятие по выработке токсичного информационного газа». Ядовитые комментарии в социальных сетях, воинствующее невежество, отсутствие толерантности и эмпатии — таковы признаки токсичного общения [4].

Еще одной коммуникативной технологией, позволяющей легко приспосабливать к конфликтной ситуации поведение в целях избегания конфликта, выхода из проблемной ситуации, выступает рефрейминг (англ. Frame - рамка) (Р. Бендлер, Д. Гриндер, 1980). Рефрейминг - это техники, позволяющие переосмыслить и перестроить механизмы восприятия и поведения с целью избегания неудачных шаблонов. На практике это приемы, позволяющие изменить точку зрения, а следовательно, восприятие события или предмета, это способ переоценки-интерпретации ситуации. Выделяют два вида рефрейминга: смысла и контекста.

1. Рефрейминг смысла — основан на синонимии, перифразах, эвфемизмах: a) Он скупой. — Я бы назвал это бережливостью. б) Меня никто не любит. — Это повод что-то изменить в своей жизни; в) Он слишком ленив. - Зато не сделает лишних ошибок.

2. Рефрейминг контекста - поиск контекста, в котором высказывание/суждение будет позитивным - поиск интерпретирующей дефиниции: Она слишком застенчива. - Зато не скажет ничего лишнего. Скромных любит начальство. 1. Утверждение: «Нерешительность - сомнение в выборе или неготовность выбирать. 2. Реакция: А) Что плохого в тщательном анализе ситуации? — рефрейминг смысла. Б) Да, он совершенно нерешителен, когда можно сделать подлость, - рефрейминг контекста ${ }^{2}$.

Следующий пример - работа с концептом «возражение». В толковых словарях - это опровергающий довод, мнение против чего-нибудь, выражение мотивированного несогласия с чем-нибудь. Возражения могут быть истинные/ложные, высказанные/скрытые. В сфере продаж это может быть сомнение в приобретении

1 Троллинг — что это такое? URL: https://ktonanovenkogo.ru/voprosy-i-otvety/trollingchto-eto-takoe.html (дата обращения: 20.09.2018).

2 Модель НЛП. URL: https://renings.ru/entsiklopediya-nlp/modeli/959-model-nlprefrejming.html (дата обращения: 20.09.2018). 
услуги, товара, запрос на дополнительную информацию. В бизнесе активно используется техника рефрейминга как инструмент работы с возражениями клиентов. В этом случае применяют такие методы, как активное слушание (пояснения при помощи уточняющих и наводящих вопросов); перефразирование/переформулирование слов собеседника; уточнение деталей; частичное согласие; техника искренней заинтересованности («я уважаю ваше мнение», «мне понятно ваше сомнение») и присоединение к возражению («действительно...»); ссылка на собственный опыт; перевод возражения в вопрос; встречные вопросы. В технологию рефрейминга также входят: техника трех «да»; техника сравнения с аналогами; взгляд на проблему с разных сторон; подход «да, зато...»; выявление скрытых возражений (мотивов и причин); взгляд в будущее; прием «именно поэтому...»; прием «представьте себе»; прием фиксации позитивных моментов ситуации и т. п. Общая модель работы с возражениями включает в себя установление контакта, формирование потребности и затем формирование ценности ${ }^{1}$.

В целом овладение техникой рефрейминга усилит личную коммуникативную безопасность в проблемной ситуации и обеспечит эластичность коммуникации.

Интересно взглянуть на эффективную коммуникацию личности комплексно, с опорой на достижения социолингвистики, коммуникавистики, культурологии. Это связано с появлением новых научных объектов на пересечении традиционных наук - психологии, социологии, лингвистики, педагогики и др. Психологи и педагоги тяготеют к общению, социологи - к коммуникации, лингвисты - к тексту, речи и дискурсу. В науке выделяют несколько подходов в разграничении первой группы понятий, согласно которым коммуникация приравнивается к общению (А. А. Леонтьев и др.), входит в структуру общения (М. С. Каган и др.). В последние годы разрабатывается еще один аспект - рассмотрение коммуникации как нелинейного процесса [2].

Классическая линейная модель коммуникативного акта исходит из идентичности когнитивных механизмов адресата и адресанта, наличия у них общего кода для понимания той или иной информации (при нарушении этого условия происходит коммуникативный шок, сбой). Но в нелинейной модели различие понимается как причина порождения и основа способа существования информации: усиливается роль опосредующих механизмов передачи информации, делается акцент на исследовании межкультурного опыта, организованного на основе принципа различия, в отличие от принципа тождества, присущего классическому пониманию коммуникации [2]. Основной задачей любого коммуникативного взаимодействия становится созидание некоего смыслового поля, в котором циркулирует разнородная информация, отражающая мысли, чувства и эмоции, формализуемые словами, изображения, звуки, жесты, мимика, т. е. вербальными и невербальными знаковыми системами. Синергийность нелинейной коммуникации позволяет принимать инакость собеседника без информационных потерь.

\footnotetext{
${ }^{1}$ Скрипты возражений в продажах. URL: https://bisdelo.ru/skripty-vozrazhenij-v-prodazhax.html\#i (дата обращения: 20.09.2019).
} 
Г. А. Иванова, И. Б. Захарова. Молодежная коммуникация в условиях современной информационной среды

Исследователем Н. С. Розовым выделены базовые фреймы в форме бинарной оппозиции с их инвариантными характеристиками, которые важны для определения социальной идентичности и вызывают наибольший резонанс в массовой коммуникации:

1) свое и чужое - фрейм, универсальный для всех этносов и наций, культур и цивилизаций; российская специфика состоит, во-первых, в высоком уровне отвержения, непризнания чужого, в отказе за чужим в праве на достоинство или даже на существование, либо в полном игнорировании и пренебрежении чужим; во-вторых, в особой легкости признания чужого своим и отказа от бывшего своего в пользу нового своего (бывшего чужого);

2) другой фрейм - высшие идеалы и польза (выгода). Для россиян характерны жесткое разделение и противопоставление «высоких», «духовных» идеалов (святынь, ценностей) и «низкой», «шкурной» пользы. Отмечается также слабая способность к их органичному и устойчивому объединению, склонность к полному принятию того или иного полюса с последующим радикальным разочарованием;

3) еще один фрейм связан с ближним кругом и государством. В России первый полюс жестко ассоциирован с демонстративно бескорыстной взаимоподдержкой, тогда как государство, напротив, - с формальным принуждением, избеганием от этого принуждения, либо с подчинением ему - беззаветной верностью и службой;

4) соотношение России и Запада является давно сложившимся фреймом, периодически возникающим в разные исторические периоды. В российском менталитете этот фрейм проявляется в неустойчивости, высокой неудовлетворенности российской действительностью, что может выражаться в полном отрицании национальных достоинств либо в чрезмерно навязчивом их превознесении [7].

При отборе содержания кейсов для обеспечения коммуникативной безопасности личности важно учитывать комплекс условий и особенностей. Во-первых, контекстуально-ситуативные, связанные с персональной и коллективной «картиной мира»: а) социально-культурные, б) половые (гендерные), в) национально-культурные, г) этические, д) индивидуально-психологические. Во-вторых, коммуникативно-лингвистические, связанные с категорией «языковая картина мира»: а) лингвокультурологические, б) лингвокогнитивные, в) психолингвистические, г) социолингвистические; д) идиолектные - характерные для конкретного человека, выражаются в особом лексиконе, грамматических особенностях, а также в идиоматике, произношении, которые характерны исключительно для данного человека.

В этике социального философа Ю. Хабермаса, развивающего идеи морального когнитивизма, истинная коммуникация трактуется как коммуникация по поводу поиска истины, каковой она становится лишь по мере обеспечения людям возможности свободного и беспристрастного обсуждения высших ценностей, которые в силу исторической изменчивости требуют постоянного спора о себе [8]. Вместо кантовского категорического императива в теории консенсуса Ю. Хабермас показывает, как овладеть коммуникативной этикой - этикой стремления к истине, категорические императивы которой формируются в языке. Целью консенсуса является не постижение истины, а достижение взаимопонимания, самого аутентичного взаимопонимания, которое характеризует «естественное» речевое общение людей 
в жизненном мире, не искаженном вторжением - антагонистических, основанных на насилии - общественных систем, поэтому завершение коммуникативного действия - сфера этических норм, утверждающих горизонт ценностных предпочтений человека [9]. Исследователь предполагает, что в современных обществах демократия как политический порядок не может опираться на субстанционально единую, как бы заранее переформированную «волю народа». Если идея коллективного самоопределения еще сохраняет свой практический смысл, то демократическая самоорганизация должна мыслиться как процесс, как процедура формирования мнений и воли народа. Легитимно не то решение, которое выражает якобы уже сформированную волю народа, но то, в обсуждении которого приняло участие наибольшее количество граждан. Характер отношений между коммуникантами предопределяет специфику общения, в котором с позиции социолингвистики выделяются: неофициальный, в терминологии В. И. Карасика — персональный (личностно ориентированный) и официальный (статусно ориентированный), или институциональный дискурс, обусловленный выполнением социальных функций («студент - преподаватель» и т. д.) [3]. В первом случае говорящий выступает как личность во всем богатстве своего внутреннего мира, во втором случае - как представитель определенного социального института. Публичное общение в любой его форме имеет официальный статус, поэтому институциональное общение - это коммуникация в ролевых масках. Но в интернет-коммуникации публичность не воспринимается как элемент институционализации. Блогеры мотивируют массовую коммуникацию (в частности, оскорбительный тон критических постов блогера «Лены Миро», которая считает, что «обращение к читателям "толстые свиньи" мотивирует сильнее, чем вежливые слова») [5]. Наиболее яркие блогеры играют роль мотиваторов социальной активности. К таким, в частности, относится Юрий Дудь, журналист, автор шоу «вДудь», который очень популярен в студенческой среде.

Важная социальная категория, обобщающая наблюдения над особенностями современной коммуникации как поликодового, полифонического (М. Бахтин) и полидискурсивного взаимодействия, - категория взаимопонимания - обрела в Новейшее время особую силу. Взаимопонимание необходимо, чтобы культурный диалог и диалог культур не превратились в симулякр. В этой ситуации особо значимым становится совершенствование информационного и коммуникативного арсенала педагога как основы эффективной социально-педагогической коммуникации, обеспечивающей социализацию студента в образовательной среде.

Изучив тенденции в области современного образования, актуализирующие проблему успешной социализации студентов, приходим к выводу, что большим потенциалом обладают гуманистические и этические коммуникативно-риторические средства и технологии (медиация, рефрейминг, ситуационный анализ и др.). Именно такие коммуникативные технологии, применяемые в организованной учебно-коммуникативной среде вуза, способствуют достижению участниками коммуникаций взаимопонимания, формирования пластичности коммуникативного поведения, обеспечения коммуникативной безопасности личности за счет овладения моделью эластичной коммуникации. 
Г. А. Иванова, И. Б. Захарова. Молодежная коммуникация в условиях современной информационной среды

Литература

1. Голоднов А. В. Лингвопрагматические особенности персуазивной коммуникации (на примере современной немецкоязычной рекламы): автореф. дис ... канд. филол. наук. СПб.: СПбГУ, 2003. 23 с.

2. Жебит В. А. Теория коммуникаций. Нелинейная коммуникация. М.: Грошев-дизайн, 2005. $200 \mathrm{c}$.

3. Карасик В. И. О типах дискурса // Языковая личность: институциональный и персональный дискурс. Волгоград, 2000. С. 5-20.

4. Наумова К. Почему «tохіс» стало словом года и что это значит для всех нас // РБК. Стиль. 2018. 29 нояб. [Электронный pecypc]. URL: https://style.rbc.ru/ life/5bfe63ef9a7947b45339dc60 (дата обращения: 20.09.19).

5. Миро Л. Биография. Личная жизнь [Электронный ресурс]. URL: https://24smi.org/celebrity/2957-lena-miro.html (дата обращения: 20.09.19).

6. Авраменко А. А., Кирсанов К. А., Рыков С. В. Надпредметное направление в деятельности вуза (на примере экологического направления): монография / под общ. ред. А. А. Авраменко. М.: Директ-Медиа, 2014. С. 257.

7. Розов Н. С. Динамическая концепция менталитета и изменчивое разнообразие российских габитусов // Идеи и идеалы. 2010. № 1(3), т. 1. С. 60-79.

8. Хабермас Ю. Современная западная теоретическая социология: реф. сб. / под ред. Н. П. Поляковой. Вып. 1. М.: ИНИОН, 1992. 134 с.

9. Хабермас Ю. Демократия. Разум. Нравственность: пер. с нем. М.: Academia, 1995. $252 \mathrm{c}$.

\section{COMMUNICATION AS A MEANS OF YOUTH'S SOCIALIZATION}

\section{Galina A Ivanova}

Cand. Sci. (Education), A/Prof.,

St. Petersburg Institute (branch) of All-Russian State University of Justice (RLA of the Ministry of Justice of Russia)

19a, $10^{\text {th }}$ line of V. O., St. Petersburg 199178, Russia

E-mail: iriza63@mail.ru

\section{Irina B. Zakharova}

Cand. Sci. (Philos.), A/Prof. of Higher School of Media Communications and Public Relations,

Peter the Great St. Petersburg Polytechnic University

29 Polytekhnicheskaya St., St. Petersburg 195251, Russia

E-mail: iriza63@mail.ru

Mass communication as one of the types of communication largely determines the essence of modern sociality and the specifics of "information society" in the post-industrial era. Against the background of the increased amount of information, the intensification of the aggressive influence of information environment it is necessary to revise the approaches to the socialization of youth through the development of new competencies that will allow young people to communicate safely, ethically and mutually profitable. A toxic information environment generates dysfunctional, toxic communications, manifested in neglect of ethical standards of interaction, lack of flexibility in communication among young people, a decrease in the level of empathy, a desire to dominate and increased verbal aggression. In general, the plasticity of the psyche is destroyed, i.e. the ability to change, switch, compensate and replenish mental stamina, and the development of social intelligence is hindered. In this regard, the development of skills of the "elastic" communication among young people is becoming a task not only of individual social institutions, such as the 
family, education and media, but also of society as a whole. In the article, we have given examples of communicative technologies that form the backbone of elastic communication aimed at understanding the concepts of personal communicative security and communicative ethics by communication participants, development of communicative consciousness and mastering rhetorical communicative behavior both in real life and in virtual space. Keywords: communication security of a person; toxic environment; elastic communication; mediation; reframing; trolling. 